\title{
Prenatal healthcare providers' Gaucher disease carrier screening practices
}

\author{
Dana Falcone, MS1, Elisabeth McCarty Wood, MS1, Michael Mennuti, MD², Sharon X. Xie, PhD², \\ Vivianna M. Van Deerlin, MD, PhD ${ }^{1}$
}

Purpose: Gaucher disease carrier screening is controversial in the medical community. The goal of this study was to explore current Gaucher disease carrier screening practices of prenatal healthcare providers.

Methods: Prenatal healthcare providers were invited by email to complete an electronic-based survey.

Results: A total of 1,454 prenatal healthcare providers, including 209 genetic counselors, 450 midwives, and 795 physicians, completed the study. The majority of genetic counselors $(n=208 / 209,>99 \%)$, physicians ( $n=415 / 450,92 \%)$, and midwives $(n=634 / 795,80 \%)$ currently offer Jewish ancestry disease carrier screening to couples in whom one or both partners are Jewish. Of providers who offer Jewish ancestry disease screening, the majority of genetic counselors ( $n=199 / 208,96 \%)$ and physicians ( $n=352 / 415,85 \%)$ always or sometimes offer Gaucher disease screening whereas the majority of midwives ( $n=357 / 634,56 \%)$ never offer Gaucher disease screening.

Conclusion: This study presents the first report of Gaucher disease carrier screening practices of the prenatal healthcare providers in North America. Our results indicate that Gaucher disease carrier screening is being offered at a high rate within the scope of Jewish ancestry-based carrier screening. This may highlight a need to move away from the debate as to whether Gaucher disease carrier screening should be offered and, instead, focus on how best to provide Gaucher disease carrier screening services.

Genet Med 2012:14(10):844-851

Key Words: carrier screening; Gaucher disease; practices; prenatal healthcare providers; survey

\section{INTRODUCTION}

Carrier screening for genetic diseases common in the Ashkenazi Jewish population has become standard of care in the prenatal and preconception settings. Recommendations for testing and the inclusion of certain disorders are available through the American College of Obstetrics and Gynecology (ACOG) ${ }^{1}$, the American College of Medical Genetics and Genomics $(\mathrm{ACMG})^{2}$, and the Society of Obstetricians and Gynecologists of $\mathrm{Canada}^{3}$. However, the various professional organizations differ in which diseases to include when offering carrier screening to individuals of Ashkenazi Jewish descent. One disease in particular that has been controversial is Gaucher disease (GD).

Mutations in glucocerebrosidase (GBA) cause GD, an autosomal recessive lysosomal storage disease with variable phenotypes ranging from a perinatal-lethal disorder to an asymptomatic form. GD is characterized by hepatosplenomegaly, anemia and thrombocytopenia, bone lesions, and pulmonary disease, with (neuropathic) or without (nonneuropathic) neurological symptoms. ${ }^{4}$ The frequency and distribution of GBA mutations varies between different ethnic and racial groups and is highest in the Ashkenazi Jewish population, where between 1 in 12 and 1 in 16 individuals are carriers.,5 One mutation, N370S, accounts for $70 \%$ of the mutant alleles found in the Ashkenazi
Jewish population and is considered a mild mutation, protective against severe neuropathic involvement. ${ }^{4}$ Less than $1 \%$ of individuals who are not of Ashkenazi Jewish descent are believed to be carriers for GD and the associated GBA mutations are more diverse. ${ }^{6}$ There is wide phenotypic variation between individuals with GD, even between patients sharing the same GBA mutation.

Due to the variable phenotype of GD, carrier screening is controversial. Currently, ACOG and Society of Obstetricians and Gynecologists of Canada do not recommend carrier screening for GD in the absence of a family history. ${ }^{1,3}$ In contrast, ACMG recommends that carrier screening for GD should be offered to all individuals of Ashkenazi Jewish descent. ${ }^{2}$ Despite the controversy over what diseases to include, the Ashkenazi Jewish carrier screening panel that is commonly offered by laboratories throughout the United States includes mutations that cause $\mathrm{GD}^{7}$.

The adoption of preconception and prenatal carrier screening in the Ashkenazi Jewish population has been high. GD carrier screening was first introduced to the Ashkenazi Jewish population in the early 1990s as part of a screening panel, which also included testing for Tay Sachs disease and cystic fibrosis. ${ }^{8}$ A pilot study in 1997 revealed that $95 \%$ of the individuals

${ }^{1}$ Department of Pathology and Laboratory Medicine, Center for Neurodegenerative Disease Research, University of Pennsylvania, Philadelphia, Pennsylvania, USA; ${ }^{2}$ Reproductive Genetics, Hospital of the University of Pennsylvania, Philadelphia, Pennsylvania, USA; ${ }^{3}$ Department of Biostatistics and Epidemiology, University of Pennsylvania, Philadelphia, Pennsylvania, USA. Correspondence: Dana Falcone (danajosephine@gmail.com) 
accepted carrier screening for the panel that included $\mathrm{GD}^{9}$. A recent study determined the carrier frequencies of 16 recessive disorders common in the Ashkenazi Jewish population, including GD, and evaluated by which diseases were selected for screening. ${ }^{10}$ The study found that all individuals selected a carrier screening panel that included GD, suggesting that the Ashkenazi Jewish population is supportive of multiple disease carrier screening panels, which include GD.

Recently, mutations in GBA have also been associated with about a fivefold increased risk of Parkinson disease (PD), a neurodegenerative disorder characterized by resting tremor, slow movements, postural instability, and rigidity. ${ }^{11}$ Exploration into the responsibility of healthcare providers to relay this new information to patients is necessary and will prove to be highly advantageous in uncovering the best way to educate patients on the implications of their genetic testing results. Before exploring opinions on disclosing information about the link between GBA mutations and PD, it would be useful to evaluate the current carrier screening practices for GD in healthcare providers. While there are a number of studies evaluating patients' acceptance and interest in carrier screening for panels of diseases including GD, there is little information concerning the extent to which healthcare providers in North America are offering GD carrier screening tests. In this study, we assessed the current GD carrier screening practices of genetic counselors, physicians, and midwives.

\section{MATERIALS AND METHODS}

\section{Participants}

Eligible participants were genetic counselors, physicians, and midwives with current experience in prenatal care. All study activities were approved for exempt status by the University of Pennsylvania Institutional Review Board. Members of the National Society of Genetic Counselors, American Medical Association, and American College of Nurse-Midwives were invited to participate in the study by email. The email invitation included a description of the purpose of the study and a link to the anonymous online survey at http://www.surveymonkey. com/. To maximize the survey response rate, $\$ 1$ was donated for every completed survey to the March of Dimes (up to a maximum of $\$ 500$ ) and participants were offered the opportunity to enter an email address in a raffle to win a prize. To ensure anonymity, email addresses entered in the raffle were not linked to the completed survey.

Genetic counselors were contacted through the National Society of Genetic Counselors listserv in December 2010 and January 2011. Approximately 470 prenatal genetic counselors subscribed to the listserv at that time and 213 responded to the survey; a response rate of $45 \%$. Midwives were contacted through the American College of Nurse-Midwives membership email list in December 2010. A total of 4,079 email invitations were sent, 3,993 emails were delivered, 1,443 emails were opened, and 882 responded to the survey; a $61 \%$ response rate of the opened emails. A sample of 18,678 prenatal care physicians was randomly selected from all physicians in the
American Medical Association Physician Masterfile with a primary specialty in obstetrics and gynecology, obstetrics, maternal fetal medicine, or reproductive endocrinology and infertility in December 2010 and January 2011. A total of 16,826 email invitations were delivered, 999 emails were opened, and 488 responded to the survey; a $49 \%$ response rate of opened emails. Healthcare professionals who did not currently provide care to preconception, or prenatal patients (e.g., gynecological oncologists, administrators, etc.), or did not complete the entire survey were excluded from the analysis. Surveys submitted by a total of 209 genetic counselors, 450 physicians, and 795 midwives were used for the final analysis.

\section{Structured survey}

A structured survey was designed based on a literature review of current prenatal carrier screening practices and ethical issues related to medical genetics. ${ }^{12-18}$ Questions were reviewed by a bioethicist, reproductive geneticist (M.M.), and biostatistician (S.X.X.) for clarity, readability, and ability to assess the goals of the study. The survey included questions about demographics, current GD carrier screening practices, current awareness of an association between GD carriers and an increased risk of PD, and opinions of healthcare providers responsibility to or not to inform patients of this association. The results from the portion of the survey looking at current awareness of an association between GD carriers and an increased risk of $\mathrm{PD}$, and opinions of healthcare providers responsibility to or not to inform patients of this association will be reported separately. Genetic counselors, physicians, and midwives were sent separate links to the survey as the initial 2-3 questions of the demographic section, assessing years of experience, and primary area of practice, were provider specific. The remainder of the survey was the same for each provider group. The survey was piloted on a total of 10 genetic counselors, midwives, and physicians and no modifications were required.

\section{Data analysis}

All data were coded and analyzed using SPSS for Windows 17.0 (SPSS, Chicago, IL). Participants were asked about the state in which they currently practice. States were then grouped into the categories shown in Table 1. Descriptive statistics were calculated for all variables measured, including frequency counts and percentages. $\chi^{2}$ tests were used to examine whether there were any significant demographic differences between genetic counselors, physicians, and midwives. Binary logistic regression was used to examine differences in variables that might be associated with offering Jewish ancestry disease carrier screening and GD carrier. For the logistic regression, residency was combined with 0-4 years of prenatal experience, age category 70+ was combined with 60-69 years, non-Caucasian ethnicities were combined and compared with Caucasian, and nonJewish religions were combined and compared with Jewish. Participants were asked if they would offer GD carrier screening in seven different scenarios. Due to the fact that $100 \%$ of genetic counselors answered yes to the scenario "Reproductive partner 
has Gaucher disease or is a known carrier", we conducted an exact logistic regression with provider type as the only predictor in the model for this question. Individuals who choose "prefer not to answer" for gender, ethnicity, age, and religion, as well as participants from Canada or who did not provide a state, were excluded from the logistic regression analysis. Statistical significance was set at the 0.05 level.

\section{Demographics}

\section{RESULTS}

The demographic characteristics of the 1,454 participants are shown in Table 1 . The majority of participants were female $(n$ $=1,229 ; 85 \%)$, Caucasian $(n=1,287 ; 89 \%)$, and Christian $(n$ $=939 ; 65 \%)$. There was a wide range of ages, years of experience in prenatal care, work setting, and US geographical region among participants. Genetic counselors, physicians, and midwives differed significantly from each other for a number of demographic factors including years of experience in prenatal care, age, gender, ethnicity, religion, and work setting. Of the 450 physicians, $71 \%(n=318)$ were general obstetrician-gynecologists, $22 \%(n=97)$ were maternal fetal medicine specialists, $4 \%(n=20)$ were general gynecologists, $3 \%(n=13)$ were reproductive endocrinology and infertility specialists, and $<1 \%$ $(n=2)$ were 'other' specialties. Midwives were asked to select all of the primary areas of practice that constituted $20 \%$ or more of their practice activity; of the 795 midwives, $97 \%(n=772)$ were in prenatal care, $78 \%(n=623)$ were in labor and delivery, $65 \%$ $(n=519)$ were in gynecological/family practice, and $10 \%(n=$ 78) were in 'other' areas of practice.

\section{Screening practices}

The majority of genetic counselors ( $n=208 / 209,>99 \%$ ), physicians $(n=415 / 450,92 \%)$, and midwives $(n=634 / 795,80 \%)$ currently offer Jewish ancestry disease carrier screening to couples in whom one or both partners are Ashkenazi Jewish. However, genetic counselors (Odds ratio $(\mathrm{OR})=75.09 ; 95 \%$ confidence interval $(\mathrm{CI})=10.02,562.53)$ and physicians $(\mathrm{OR}=4.41 ; \mathrm{CI}=$ $2.34,8.33)$ were significantly more likely to offer Jewish ancestry disease carrier screening compared with midwives $\left(\chi^{2}(2, N\right.$ $=1,389)=82.03, P<0.001)$. Using logistic regression to control for all demographic factors listed in Table 1, prenatal years of experience $\left(\chi^{2}(5, N=1,389)=16.04, P=0.007\right)$, work setting $\left(\chi^{2}(3, N=1,389)=16.09, P=0.001\right)$, age $\left(\chi^{2}(4, N=1,389)=\right.$ $12.43, P=0.014)$, gender $\left(\chi^{2}(1, N=1,389)=10.77, P=0.001\right)$, and US region $\left(\chi^{2}(5, N=1,389)=29.76, P<0.001\right)$ were also found to influence whether participants offered Jewish ancestry disease carrier screening. Participants with $0-4(\mathrm{OR}=0.23$; $\mathrm{CI}=0.01, .52)$ and $5-9(\mathrm{OR}=0.25 ; \mathrm{CI}=0.12,0.55)$ years of experience in prenatal care were significantly associated with reduced odds of offering Jewish ancestry disease carrier screening compared with individuals with over 25 years of experience. Males ( $\mathrm{OR}=0.30 ; \mathrm{CI}=0.15,0.62)$ were significantly less likely to offer Jewish ancestry disease screening compared with females. Individuals of ages $40-49(\mathrm{OR}=3.48 ; \mathrm{CI}=1.72,7.03)$ and $50-59(\mathrm{OR}=2.04 ; \mathrm{CI}=1.15,3.61)$ years were significantly more likely to offer Jewish ancestry disease carrier screening compared with individuals over the age of 60 years. In addition, participants that practiced in a private practice $(\mathrm{OR}=2.03$; $\mathrm{CI}$ $=1.33,3.12)$ or university medical center $(\mathrm{OR}=2.26$; $\mathrm{CI}=1.25$, 4.07) compared with those who practiced in public medical facilities, and participants who practiced in the northeast (OR $=5.71 ; \mathrm{CI}=1.95,16.72$ ) compared with the west were significantly more likely to offer Jewish ancestry disease screening.

Of those providers who offer Jewish ancestry disease screening, the majority of genetic counselors $(n=199 / 208,96 \%)$ and physicians ( $n=352 / 415,85 \%)$ always or sometimes (always/ sometimes) offer GD carrier screening whereas the majority of midwives ( $n=357 / 634,56 \%)$ never offer GD carrier screening (Figure 1). Similar to the findings for offering Jewish ancestry disease screening, genetic counselors $(\mathrm{OR}=75.18 ; \mathrm{CI}=25.86$, $218.54)$ and physicians $(\mathrm{OR}=7.92 ; \mathrm{CI}=5.06,12.39)$ were significantly more likely to always/sometimes offer GD carrier screening compared with midwives $\left(\chi^{2}(2, N=1,200)=224.75\right.$, $P<0.001)$. Work setting $\left(\chi^{2}(3, N=1,200)=9.45, P=0.024\right)$, US region of practice $\left(\chi^{2}(5, N=1,200)=40.85, P<0.001\right)$, and religion $\left(\chi^{2}(1, N=1,200)=14.84, P<0.001\right)$ were found to influence whether participants always/sometimes include GD disease when offering Jewish ancestry-based carrier screening. Participants that practiced in a private practice $(\mathrm{OR}=1.65$; CI $=1.11,2.45)$ or university medical center $(\mathrm{OR}=2.04 ; \mathrm{CI}=1.26$, 3.31) compared with those who practiced in public medical facilities, and participants who practiced in the northeast (OR $=2.12 ; \mathrm{CI}=1.29,3.50)$ or mid-Atlantic $(\mathrm{OR}=2.94 ; \mathrm{CI}=1.83$, 4.70) compared with the west were significantly more likely to always/sometimes include GD disease when offering Jewish ancestry-based carrier screening. Individuals who reported their religion as Jewish $(\mathrm{OR}=2.71 ; \mathrm{CI}=1.59,4.64)$ were significantly more likely to always/sometimes offer GD carrier screening compared with individuals of other religions.

\section{GD education practices}

The majority of genetic counselors ( $n=172 / 199 ; 86 \%)$ and physicians $(n=231 / 352 ; 66 \%)$ indicated that their patients always or sometimes receive GD education prior to GD carrier screening, compared with $45 \%$ of midwives $(n=125 / 277)$. The number of providers that indicated that their patients receive GD education after carrier screening was increased compared with the number providing education before screening for all three provider groups with $89 \%$ of genetic counselors $(n=177 / 199)$, $86 \%$ of physicians $(n=303 / 352)$, and $68 \%$ of midwives $(n=$ 187/277) choosing always or sometimes (Figure 2).

Healthcare providers were asked to indicate all individuals who provide GD education both prior to and after GD carrier screening. Participants indicated that the majority of GD education was provided by genetic counselors both prior to $(n=451 / 528,85 \%)$ and after $(n=638 / 667,96 \%)$ GD carrier screening. In addition, prior to GD carrier screening, 36\% $(n=192 / 528)$ of providers indicated that GD education was provided by the Obstetrician/ Gynecologist or midwife of the patient and 9\% $(n=45 / 528)$ indicated that other sources of education were used including a staff 
Table 1 Demographic characteristics of participants

\begin{tabular}{|c|c|c|c|c|c|c|c|}
\hline Characteristic & $\begin{array}{c}\text { Total } \\
(n=1,454)\end{array}$ & $\begin{array}{l}\text { Genetic counselors } \\
\qquad(n=209)\end{array}$ & $\begin{array}{l}\text { Physicians } \\
(n=450)\end{array}$ & $\begin{array}{c}\text { Midwives } \\
(n=795)\end{array}$ & $\begin{array}{l}\text { Pearson } \chi^{2} \\
\text { value }\end{array}$ & $\begin{array}{l}\text { Degrees of } \\
\text { freedom }\end{array}$ & $P$ \\
\hline & $n(\%)$ & $n(\%)$ & $n(\%)$ & $n(\%)$ & & & \\
\hline Years in prenatal care & & & & & 116.74 & 10 & $<.001$ \\
\hline Resident & $21(1)$ & - & $21(5)^{a}$ & - & & & \\
\hline $0-4$ & $293(20)$ & $95(46)$ & $44(10)$ & $154(19)$ & & & \\
\hline $5-9$ & $247(17)$ & $46(22)$ & $69(15)$ & $132(17)$ & & & \\
\hline $10-14$ & $286(20)$ & $28(13)$ & $89(20)$ & $169(21)$ & & & \\
\hline $15-19$ & $206(14)$ & $16(8)$ & $66(15)$ & $124(16)$ & & & \\
\hline $20-24$ & $176(12)$ & $12(6)$ & $76(17)$ & $88(11)$ & & & \\
\hline $25+$ & $225(15)$ & $12(6)$ & $85(19)$ & $128(16)$ & & & \\
\hline Age (years) & & & & & 350.99 & 8 & $<.001$ \\
\hline $20-29$ & $121(8)$ & $75(36)$ & $12(3)$ & $34(4)$ & & & \\
\hline $30-39$ & $351(24)$ & $81(39)$ & $93(21)$ & $177(22)$ & & & \\
\hline $40-49$ & $348(24)$ & $34(16)$ & $152(34)$ & $162(20)$ & & & \\
\hline $50-59$ & $480(33)$ & $17(8)$ & $139(31)$ & $324(41)$ & & & \\
\hline $60-69$ & $140(10)$ & $1(1)$ & $45(10)$ & $94(12)$ & & & \\
\hline $70+^{b}$ & $9(1)$ & $0(0)$ & $5(1)$ & $4(1)$ & & & \\
\hline Prefer not to answerc & $5(<1)$ & $1(1)$ & $4(1)$ & $0(0)$ & & & \\
\hline Gender & & & & & 457.99 & 2 & $<.001$ \\
\hline Male & $219(15)$ & $11(5)$ & $202(45)$ & $6(1)$ & & & \\
\hline Female & $1,229(85)$ & $196(94)$ & $245(55)$ & $788(99)$ & & & \\
\hline Prefer not to answer & $6(<1)$ & $2(1)$ & $3(1)$ & $1(<1)$ & & & \\
\hline Ethnicityd & & & & & 51.52 & 2 & $<.001$ \\
\hline Caucasian & $1,287(89)$ & $195(93)$ & $358(80)$ & $734(92)$ & & & \\
\hline African American/black & $37(3)$ & $2(1)$ & $16(4)$ & $19(2)$ & & & \\
\hline Asian & $60(4)$ & $8(4)$ & $43(10)$ & $9(1)$ & & & \\
\hline Hispanic & $40(3)$ & $0(0)$ & $22(5)$ & $18(2)$ & & & \\
\hline Prefer not to answer ${ }^{c}$ & $18(1)$ & $3(1)$ & $8(2)$ & $7(1)$ & & & \\
\hline Other & $12(1)$ & $1(1)$ & $3(1)$ & $8(1)$ & & & \\
\hline Religion & & & & & 70.83 & 8 & $<.001$ \\
\hline Christian & $939(65)$ & $119(57)$ & $277(62)$ & $543(68)$ & & & \\
\hline Jewish & $179(12)$ & $27(13)$ & $90(20)$ & $62(8)$ & & & \\
\hline Atheist/agnostic/none & $125(9)$ & $36(17)$ & $20(4)$ & $69(9)$ & & & \\
\hline Other & $92(6)$ & $8(4)$ & $33(7)$ & $51(6)$ & & & \\
\hline Prefer not to answer & $119(8)$ & $19(9)$ & $30(7)$ & $70(9)$ & & & \\
\hline Work setting & & & & & 140.36 & 6 & $<.001$ \\
\hline Private practice & $569(39)$ & $41(20)$ & $202(45)$ & $326(41)$ & & & \\
\hline $\begin{array}{l}\text { Public hospital/medical } \\
\text { facility }\end{array}$ & $327(22)$ & $83(40)$ & $56(12)$ & $188(24)$ & & & \\
\hline University medical center & $295(20)$ & $60(29)$ & $133(30)$ & $102(13)$ & & & \\
\hline Other & $269(19)$ & $25(12)$ & $59(13)$ & $179(23)$ & & & \\
\hline US regione,f & & & & & 18.15 & 10 & .053 \\
\hline West & $301(21)$ & $36(18)$ & $89(20)$ & $176(23)$ & & & \\
\hline Midwest & $298(21)$ & $48(24)$ & $96(22)$ & $154(20)$ & & & \\
\hline
\end{tabular}

Notes on $\chi^{2}$ analysis: ${ }^{\mathrm{a} C o m b i n e d ~ w i t h ~ 0-4 ~ y e a r s ~ e x p e r i e n c e ; ~}{ }^{\mathrm{b}} \mathrm{Combined}$ with 60-69 years of age; ${ }^{\mathrm{C} E x c l u d e d}$ from analysis; ${ }^{\mathrm{d}}$ Non-Caucasian ethnicities combined;

eNo response from 32 participants; 'West: CO, WY, UT, CA, NV, ID, OR, WA, MT, AK, HI; Midwest: OH, MI, IN, WI, IL, MN, Al, MO, ND, SD, KS, NE; Mid-Atlantic: NY, NJ, PA, DE, DC, MD; South: VA, WV, KY, TN, NC, SC, GA, FL, AL, MS, AR, LA; Northeast: ME, NH, VT, MA, CT, RI; Southwest: TX, OK, NM, AZ. 
Table 1 (Continued)

\begin{tabular}{|c|c|c|c|c|c|c|}
\hline & $\begin{array}{c}\text { Total } \\
(n=1,454)\end{array}$ & $\begin{array}{l}\text { Genetic counselors } \\
\qquad(n=209)\end{array}$ & $\begin{array}{l}\text { Physicians } \\
(n=450)\end{array}$ & $\begin{array}{l}\text { Midwives } \\
(n=795)\end{array}$ & $\begin{array}{l}\text { Pearson } \chi^{2} \\
\text { value }\end{array}$ & $\begin{array}{l}\text { Degrees of } \\
\text { freedom }\end{array}$ \\
\hline Mid-Atlantic & $292(21)$ & $48(24)$ & $98(22)$ & $146(19)$ & & \\
\hline South & $260(18)$ & $27(14)$ & $69(16)$ & $164(21)$ & & \\
\hline Northeast & $163(12)$ & $15(8)$ & $57(13)$ & $91(12)$ & & \\
\hline Southwest & $99(7)$ & $17(9)$ & $30(7)$ & $52(7)$ & & \\
\hline Canada & $9(1)$ & $9(5)$ & $0(0)$ & $0(0)$ & & \\
\hline
\end{tabular}

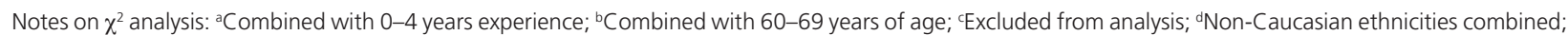

eNo response from 32 participants; 'West: CO, WY, UT, CA, NV, ID, OR, WA, MT, AK, HI; Midwest: OH, MI, IN, WI, IL, MN, Al, MO, ND, SD, KS, NE; Mid-Atlantic: NY, NJ, PA, DE, DC, MD; South: VA, WV, KY, TN, NC, SC, GA, FL, AL, MS, AR, LA; Northeast: ME, NH, VT, MA, CT, RI; Southwest: TX, OK, NM, AZ.

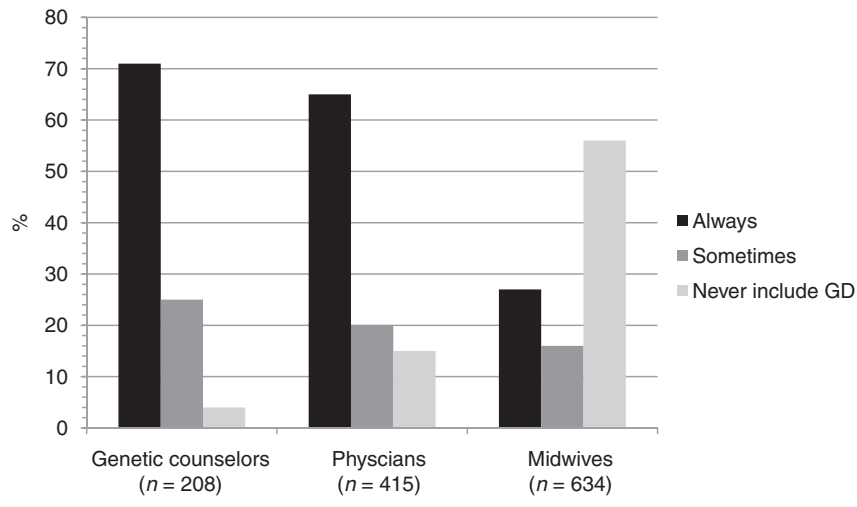

Figure 1 How often healthcare providers include Gaucher disease carrier screening when offering Jewish ancestry disease carrier screening.

nurse or nurse practitioner $(n=28)$, written material $(n=9)$, geneticist $(n=4)$, medical assistant $(n=3)$, physician assistant $(n=2)$, or perinatalogist/maternal fetal medicine $(n=2)$. After GD carrier screening, $17 \%(n=114 / 667)$ of providers indicated that GD education was provided by Obstetrician/Gynecologist or midwife of the patient and $3 \%(n=21 / 667)$ indicated that other sources of education were used including a geneticist $(n=$ 8 ), perinatologist/maternal fetal medicine $(n=7)$, staff nurse ( $n$ $=4)$, or physician assistant $(n=2)$.

\section{GD screening settings}

Healthcare providers were asked if based on their current practices they would offer GD carrier screening for seven different scenarios. Overall, the majority of healthcare providers $(97 \% ; n$ $=1,415)$ indicated that they would offer GD in one or more of the possible scenarios. The patient having a family history of GD was the most frequently selected option, followed very closely by the reproductive partner having GD or being a known carrier, the reproductive partner having a family history of GD, and the patient requesting the test (Table 2). Almost three-quarters of providers stated that they would offer GD carrier screening if the patient was Ashkenazi Jewish and almost two-thirds would offer screening if the reproductive partner was Ashkenazi Jewish. Only one-third of healthcare providers reported that they would offer GD carrier screening if the patient requested all available tests. Midwives were significantly more likely to offer genetic testing in situations where the patient specifically

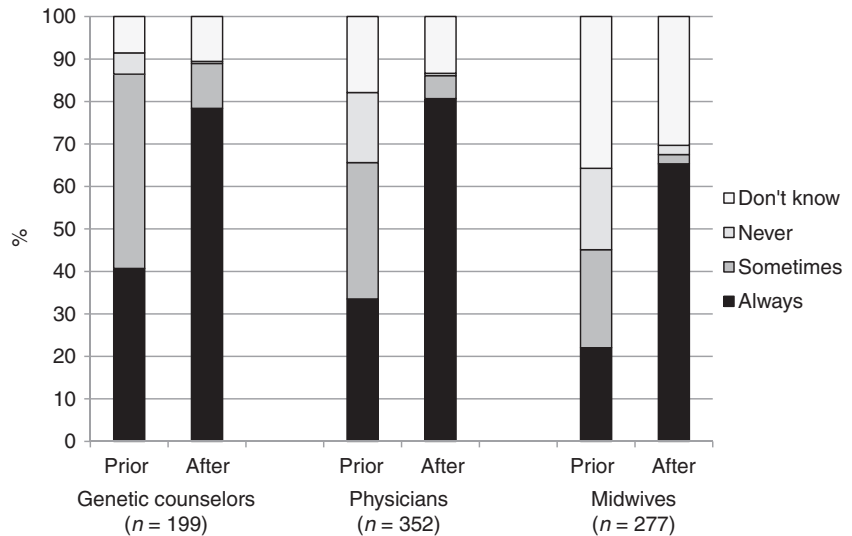

Figure 2 How often patients receive Gaucher disease education prior to and after carrier screening.

requested GD carrier screening compared with physicians (OR $=0.41, \mathrm{CI}=0.28,0.77)$ or genetic counselors $(\mathrm{OR}=0.47, \mathrm{CI}$ $=0.28,0.77)\left(\chi^{2}(2, N=1,389)=20.27, P<0.001\right)$. Midwives were less likely than both physicians and genetic counselors to offer GD carrier testing in situations in which the patient (physician: $\mathrm{OR}=4.05, \mathrm{CI}=2.69,6.09$; genetic counselors: $\mathrm{OR}$ $\left.=8.33, \mathrm{CI}=4.67,14.82 ; \chi^{2}(2, N=1,389)=102.37, P<0.001\right)$ or reproductive partner (physician: $\mathrm{OR}=2.39, \mathrm{CI}=1.71,3.35$; genetic counselors: $\mathrm{OR}=3.24, \mathrm{CI}=2.13,4.93 ; \chi^{2}(2, N=1,389)$ $=48.16, P<0.001)$ was Ashkenazi Jewish. Midwives were also less likely than both physicians and genetic counselors to offer GD carrier testing in situations where the reproductive partner was a known GD carrier or had GD (physician: $\mathrm{OR}=42.59, \mathrm{CI}$ $=7.81$, infinity; genetic counselors: $\mathrm{OR}=3.86, \mathrm{CI}=2.22,7.10$, exact test $P$ value $<0.0001)$ or if the reproductive partner had a family history of GD (physician: $\mathrm{OR}=3.44, \mathrm{CI}=1.94,6.11$; genetic counselors: $\mathrm{OR}=6.09, \mathrm{CI}=2.72,13.64 ; \chi^{2}(2, N=1,389)$ $=39.70, P<0.001)$.

\section{DISCUSSION}

This study presents the first report of GD carrier screening practices of prenatal healthcare providers in North America. Offering GD carrier screening in the preconception and prenatal settings in the absence of a family history remains controversial. The National Institutes of Health (NIH) Technology Assessment Panel on GD recommends against population carrier screening due to the broad range of clinical outcomes and 
Table 2 Based on your current practices please specify whether you would offer your patient carrier screening for Gaucher disease for each of the following situations

\begin{tabular}{|c|c|c|c|c|c|c|c|c|c|}
\hline & \multicolumn{3}{|c|}{ Genetic counselors \% (n) } & \multicolumn{3}{|c|}{ Physicians \% (n) } & \multicolumn{3}{|c|}{ Midwives \% (n) } \\
\hline & Yes & No & $\begin{array}{l}\text { Don't } \\
\text { know }\end{array}$ & Yes & No & $\begin{array}{l}\text { Don't } \\
\text { know }\end{array}$ & Yes & No & $\begin{array}{l}\text { Don't } \\
\text { know }\end{array}$ \\
\hline Patient requests the test & 75 (157) & $10(20)$ & $15(32)$ & $85(380)$ & $4(20)$ & $11(50)$ & $90(712)$ & $2(16)$ & $8(64)$ \\
\hline $\begin{array}{l}\text { Patient has a family history of } \\
\text { Gaucher disease }\end{array}$ & $>99(208)$ & $0(0)$ & $<1(0)$ & $97(435)$ & $1(4)$ & $2(9)$ & $90(717)$ & $2(13)$ & $8(65)$ \\
\hline Patient is Ashkenazi Jewish & 89 (185) & $7(14)$ & $5(10)$ & $85(381)$ & $8(35)$ & $7(32)$ & $60(475)$ & $11(89)$ & $29(228)$ \\
\hline $\begin{array}{l}\text { Reproductive partner has Gaucher } \\
\text { disease or is a known carrier }\end{array}$ & $100(209)$ & $0(0)$ & $0(0)$ & $96(434)$ & $2(7)$ & $2(9)$ & $88(696)$ & $2(16)$ & $10(79)$ \\
\hline $\begin{array}{l}\text { Reproductive partner is Ashkenazi } \\
\text { Jewish }\end{array}$ & $71(148)$ & $16(34)$ & $13(27)$ & $73(329)$ & $15(69)$ & $11(51)$ & $55(429)$ & $15(115)$ & $31(241)$ \\
\hline $\begin{array}{l}\text { Patient requests all available } \\
\text { prenatal screening tests }\end{array}$ & $23(47)$ & $37(78)$ & $40(84)$ & $33(147)$ & $40(175)$ & $27(120)$ & $35(270)$ & $34(520)$ & $31(244)$ \\
\hline
\end{tabular}

uncertain prognosis, lack of public and professional awareness of GD, and the availability of effective treatment. ${ }^{19}$ Consistent with the NIH recommendations, ACOG and Society of Obstetricians and Gynecologists of Canada do not recommend population-based carrier screening for GD. ${ }^{1,3}$ However, ACMG recommends that carrier screening for GD should be offered to all individuals of Ashkenazi Jewish descent. ${ }^{2}$ The clinical utility of offering GD carrier screening is also debatable as the most common mutation in the Ashkenazi Jewish population, N370S, usually leads to a mild or symptomless phenotype and those who are affected can be effectively treated with enzyme replacement therapy. ${ }^{20}$ In response to the ACMG recommendations, one author expressed concerns that while individuals should be informed of all available tests and arrive at their own, independent choice, it cannot be ignored that carrier screening for GD, a low penetrance, treatable disease, may lead to questionable pregnancy terminations. ${ }^{21}$ However, the ACMG guidelines were established through a conference that was attended by medical professionals and community representatives. The community representatives, including GD support groups, advocated that couples should be given choices and recommended that education and support for GD carrier screening be provided. ${ }^{22}$ The NIH technology assessment panel, while recommending against populationbased carrier screening, stated that cultural mores within specific communities should be considered and may justify screening. ${ }^{19}$

Despite the controversy, carrier screening for GD is available and is often included in Ashkenazi Jewish ancestry multiple disease carrier screening panels offered by laboratories throughout the US ${ }^{7}$. In addition, due to the lobbying of a special interest group, starting in 2012 the state of Illinois will begin to require that newborn screening include GD. ${ }^{23,24} \mathrm{~A}$ few studies have examined the interest of general population in and uptake of GD carrier screening but, to the best of our knowledge, no studies have examined if prenatal healthcare providers are offering GD carrier screening in North America. ${ }^{9}{ }^{10}$ Our results indicate that GD carrier screening is being offered at a high rate within the scope of Jewish ancestry-based carrier screening. This finding is consistent with the fact that GD is often included in carrier screening panels. Interestingly, healthcare providers that listed their religion as Jewish were significantly more likely to offer GD carrier screening compared with healthcare providers that were non-Jewish. This finding is consistent with early studies that indicated the adoption of carrier screening for GD in the Ashkenazi Jewish population is high and suggests healthcare providers who are Jewish are more likely to support GD carrier screening.

Overall, the current GD carrier screening practices of physicians and genetic counselors tended to be similar, while more apparent differences occurred within the midwife population. The majority of genetic counselors and physicians who offer Jewish ancestry disease carrier screening always or sometimes include GD, whereas the majority of midwives never include GD. It cannot be determined from this study if the variation in offering GD carrier screening is related to the different guidelines published by ACOG and ACMG, but it is possible the different guidelines published by ACOG and ACMG may play a role. Further research could elucidate whether ACOG or ACMG guidelines play a role in explaining the differing clinical practices. Similarly, the majority of genetic counselors and physicians indicated that their patients receive education on GD before screening compared with less than half of the patients of midwives. While the majority of midwives indicated that their patients receive education on GD after carrier screening, this number was still less than the patients of genetic counselor and physician. Those participants that indicated they are providing GD education after carrier screening are most likely only offering education to those individuals who are identified as carriers. The reasons for the differences in GD carrier screening and education practices between genetic counselors/physicians and midwives cannot be determined from this study. Understanding 
the GD carrier screening practices within the midwife profession may warrant further study.

Demographic characteristics also influenced whether healthcare providers offered Jewish ancestry screening or included GD when offering screening. Providers who had more years of experience in prenatal care, were between the ages of 40-59 years, were female, practiced in the northeast, or who practiced in a private practice or university medical center were more likely to offer Jewish ancestry screening. Providers who practiced in a private practice or university medical center, or in the mid-Atlantic or Northeast were significantly more likely to include GD when offering Jewishbased carrier screening. Whether these differences are due to the different recommendations set forth by ACOG and ACMG remains to be seen. The differences observed between various US regions in offering Jewish-based ancestry screening and including GD when offering screening may be due to the number of individuals of Jewish ancestry who reside in these areas, with the northeast and mid-Atlantic regions having a higher Jewish population. ${ }^{25}$ This again reflects the rate of acceptance of ancestry-based carrier screening, including $\mathrm{GD}$, in this population.

The majority of healthcare providers would offer GD carrier screening in at least one of the seven listed scenarios (Table 2). However, there were noted differences between midwives, physicians, and genetic counselors for the possible scenarios in which they would offer GD screening. Genetic counselors and physicians were less likely than midwives to provide GD carrier screening because the patient specifically requested the test. While the difference between genetic counselors and physicians was not statistically significant, of all three groups, genetic counselors were the least likely to offer GD carrier screening because the patient requested the test. It is possible that a proportion of genetic counselor respondents may be anticipating that some individuals who request GD carrier screening may not actually be appropriate candidates for GD screening and therefore either would not offer GD carrier screening or were unsure if they would offer screening. While the majority of midwives would offer GD carrier screening, they were still significantly less likely to offer screening in scenarios relating to Jewish ancestry, family history of GD, or known carrier status in the reproductive partner than physicians and genetic counselors. This finding suggests that either their current practices do not include providing GD carrier screening in those given scenarios, or that midwives are less aware of these factors as indicators for GD carrier screening, which in turn indicates a need for genetics education. Many authors have echoed the need to increase genetics education for primary care providers, including nurses, and efforts to define genetic competencies and improve genetics education are underway. ${ }^{26-28}$

\section{Study limitations}

The introductory email invitation describing the study stated that the purpose of the study was to gather information about current GD carrier screening practices. It is possible that there is a response bias if individuals with experience and familiarity with GD carrier screening were more likely to respond to the survey. We included a total of 209 genetic counselors, 450 physicians, and 795 midwives in the final analysis, which represented 14,31 , and $55 \%$ of our study population, respectively. The provider population of this study is not representative of the obstetric provider population in the United States. The relatively low number of obstetricians who participated compared with midwives appears to relate to the low portion of emails that were opened by the physician group. This may be due to the fact that the midwives were accessed through their primary professional organization whereas the obstetricians were accessed through the American Medical Association Physician Masterfile. However, we considered the response rate of $49 \%$ to be good among physicians who opened the email. The design of this study allowed for differences in GD carrier screening practices between the various healthcare professionals to be observed, but did not allow for ascertainment of the reasons for these differences.

\section{CONCLUSIONS}

The results of this study indicate that GD carrier screening is commonly offered in the prenatal and preconception setting. In addition, GD carrier screening has been available for over 20 years, has been widely accepted by the Ashkenazi Jewish population, and is commonly included in Jewish ancestry carrier screening panels offered by laboratories. This may highlight a need to move away from the debate as to whether GD carrier screening should be offered and, instead, focus on how best to provide GD carrier screening services and address whether PD risk information should be included. It may be reasonable to recommend detailed genetic counseling regarding GD before offering carrier screening so that individuals can make a truly informed decision. The counseling should include a discussion about (i) the possible difficulty of having to make a decision on whether to pursue prenatal diagnosis and possible termination for a condition with reduced penetrance, variable severity, and effective treatment and (ii) that carrier screening for GD may reveal that an individual has a mild or asymptomatic form of GD. The authors are currently conducting further research to explore the opinions of general public on GD carrier screening information and services in order to further guide GD carrier screening recommendations.

\section{ACKNOWLEDGMENTS}

We would like to thank the Penn Center for the Integration of Genetic Healthcare Technologies (CIGHT) for supporting our pilot study through grant $\mathrm{NIH} \mathrm{P50} \mathrm{HG004487} \mathrm{from} \mathrm{the} \mathrm{National} \mathrm{Human}$ Genome Research Institute. The study was supported partially by AG-10124 (the Alzheimer Disease Core Center) and NS-053488 (the Morris K. Udall Parkinson Disease Research Center of Excellence). We would also like to thank Arthur Caplan, PhD, for his review of the study survey. 


\section{DISCLOSURE}

The authors declared no conflict of interest.

\section{REFERENCS}

1. ACOG Committee Opinion No. 442. Preconception and prenatal carrier screening for genetic diseases in individuals of Eastern European Jewish descent. Obstet Gynecol 2009;114:950-953.

2. Gross SJ, Pletcher BA, Monaghan KG; Professional Practice and Guidelines Committee. Carrier screening in individuals of Ashkenazi Jewish descent. Genet Med 2008;10:54-56.

3. Langlois S, Wilson RD; Genetics Committee of the Society of Obstetricians and Gynaecologists of Canada (SOGC); Prenatal Diagnosis Committee of the Canadian College of Medical Geneticists (CCMG). Carrier screening for genetic disorders in individuals of Ashkenazi Jewish descent. J Obstet Gynaecol Can 2006;28:324-343.

4. Beutler E, Grabowski GA. Gaucher disease. In: Scriver C, Beaudet AL, Sly WS, Valle D (eds). The Metabolic and Molecular Bases of Inherited Disease. 8th edn. McGraw-Hill: New York, 2001:3635-3668.

5. Gan-Or Z, Giladi N, Rozovski U, et al. Genotype-phenotype correlations between GBA mutations and Parkinson disease risk and onset. Neurology 2008;70:2277-2283.

6. Sidransky E, Nalls MA, Aasly JO, et al. Multicenter analysis of glucocerebrosidase mutations in Parkinson's disease. N Engl J Med 2009;361:1651-1661.

7. Leib JR, Gollust SE, Hull SC, Wilfond BS. Carrier screening panels for Ashkenazi Jews: is more better? Genet Med 2005;7:185-190.

8. Zinberg RE, Kornreich R, Edelmann L, Desnick RJ. Prenatal genetic screening in the Ashkenazi Jewish population. Clin Perinatol 2001;28: 367-382.

9. Eng CM, Schechter C, Robinowitz J, et al. Prenatal genetic carrier testing using triple disease screening. JAMA 1997;278:1268-1272.

10. Scott SA, Edelmann L, Liu L, Luo M, Desnick RJ, Kornreich R. Experience with carrier screening and prenatal diagnosis for 16 Ashkenazi Jewish genetic diseases. Hum Mutat 2010;31:1240-1250.

11. Goker-Alpan O, Schiffmann R, LaMarca ME, Nussbaum RL, MclnerneyLeo A, Sidransky E. Parkinsonism among Gaucher disease carriers. J Med Genet 2004:41:937-940.

12. Shields $A E$, Levy $D E$, Blumenthal $D$, et al. Primary care physicians' willingness to offer a new genetic test to tailor smoking treatment, according to test characteristics. Nicotine Tob Res 2008;10:1037-1045.

13. Institute NHGR. Online Education Kit: Duty to Warn. http://www.genome. gov/pfv.cfm?pagelD=2501990. Accessed 4 August 2010.
14. Miller FA, Hayeems RZ, Bombard Y, et al. Clinical obligations and public health programmes: healthcare provider reasoning about managing the incidental results of newborn screening. J Med Ethics 2009;35:626-634.

15. Pencarinha DF, Bell NK, Edwards JG, Best RG. Ethical issues in genetic counseling: a comparison of M.S. counselor and medical geneticist perspectives. J Genet Couns 1992;1:19-30.

16. Wertz DC, Fletcher JC. Ethics and medical genetics in the United States: a national survey. Am J Med Genet 1988;29:815-827.

17. Morgan MA, Driscoll DA, Mennuti MT, Schulkin J. Practice patterns of obstetrician-gynecologists regarding preconception and prenatal screening for cystic fibrosis. Genet Med 2004;6:450-455.

18. Falk MJ, Dugan RB, O'Riordan MA, Matthews AL, Robin NH. Medical Geneticists' duty to warn at-risk relatives for genetic disease. Am J Med Genet A 2003;120A:374-380.

19. Gaucher Disease. Current issues in diagnosis and treatment. NIH technology assessment panel on gaucher disease. JAMA 1996;275: 548-553

20. Borry P, Clarke A, Dierickx K. Look before you leap. Carrier screening for type 1 Gaucher disease: difficult questions. Eur J Hum Genet 2008;16:139-140.

21. Levy-Lahad E, Zuckerman S, Sagi M. Response to ACMG guideline: carrier screening in individuals of Ashkenazi Jewish decent. Genet Med 2008; 10:462; author reply 463.

22. Gross SJ, Pletcher BA, Monaghan KG. Response to Levy-Lahad letter. Genet Med 2008; 10:463.

23. National Newborn Screening Status Report. 2011. http://genes-r-us. uthscsa.edu/nbsdisorders.pdf. Accessed 29 November 2011.

24. The Evanosky Foundation. 2011. "Expanded Newborn Screening Through SB1566". http://www.evanoskyfoundation.org/7083/5020.html. Accessed 29 November 2011.

25. U.S. Census Bureau. Statistical Abstract of the United States: 2012, "Table 77 - Christian Church Adherents and Jewish Population, States." Section 1, Population, Page 62. http://www.census.gov/compendia/statab/cats/ population/religion.html. Accessed 14 December 2011.

26. Lewis JA, Calzone KM, Jenkins J. Essential nursing competencies and curricula guidelines for genetics and genomics. MCN Am J Matern Child Nurs 2006;31:146-153; quiz, 154-155.

27. Burke W. Genetic testing in primary care. Annu Rev Genomics Hum Genet 2004;5:1-14.

28. Suther S, Goodson P. Barriers to the provision of genetic services by primary care physicians: a systematic review of the literature. Genet Med 2003;5:70-76. 